\title{
CLINICO-DEMOGRAHIC PROFILE, TREATMENT OUTLINE AND CLINICAL OUTCOME OF 236 CONFIRMED HOSPITALIZED COVID- 19 PATIENTS: A MULTI-CENTERED DESCRIPTIVE STUDY IN DHAKA, BANGLADESH
}

\author{
QT ISLAM ${ }^{1}$, HT HOSSAIN 2 , FR FAHIM ${ }^{3}$, MU RASHID ${ }^{4}$
}

\begin{abstract}
:
Introduction :In Bangladesh, the first confirmed case of COVID1 9 was detectedon 8th March'2020, almost 3 months after the initial outbreak in late December' 2019 in Wuhan, China.The number of affected cases and deaths both have become exponential during this global pandemic. Clinical data on COVID 19 in Bangladesh is still lacking. The objective of our study was to evaluate clinico-demograhic Profile, treatment Outline \& clinical outcome within a defined period among COVID-19 Bangladeshi Patients.

Methods: We conducted a retrospective multicenter descriptive study on epidemiological \& clinical profile along with treatment outcomes of 236 Rt-PCR confirmed patients of COVID 19 from COVID dedicated units of 3 hospitals- Dhaka Medical College Hospital (DMCH)(n-87), Kuwait Bangladesh Moitry Hospital ( KBMH)(n-50),Popular Medical College Hospital ( PMCH)(n-99) during the period of May to July 2020 with a pre determined case record form.

Results: Among the total 236 patients, highest percentage of patients (26\%) belonged to 50-59 years age range, however it was found that no age was immune.Regarding gender distribution, two-third patients were male (65\%) \& one-third patients were female (35\%). The predominant symptoms of our enrolled patients were fever (89\%), cough (85\%) \& dyspnea (76\%), fatigue (23\%), chest pain (23\%)\& anosmia (19.5\%), followed by gastro-intestinal symptoms. Almost half of the patients had been suffering from Hypertension (48\%) and Diabetes (47\%) Regarding treatment, 100\% patients received tromboprophylaxis with low molecular weight Heparin (LMWH)\& around $2 / 3$ patients received steroid in different forms following treatment protocol of our national guideline. $20 \%$ patients required ICU support \& death rate was 4.7\%. Around two-third patients could be discharged in < 10 days' time.

Conclusion: Covid-19 in Bangladesh is presented in adult male with fever, cough and dyspnoea predominantly with occasional lack of taste and smell. Supportive care was effective with predominantly good outcome
\end{abstract}

Key Words: COVID1 9, global pandemic, clinico-demograhic Profile

Received: 15 March 2020

Accepted: 12 June 2020

DOI: https://doi.org/10.3329/bjm.v31i2.48532

\section{Introduction:}

The first confirmed case of COVID-19 was detected in Bangladesh on $8^{\text {th }}$ March'2020 after almost 3 months after the initial outbreak of pandemic in late December' 2019 in Wuhan, China. During these 3 months period, while listening to the devastating news updates of COVID- 19 worldwide, the wishful thinking of our Bangladeshi people was, COVID- 19 might spare us. But finally, COVID- 19 did not spare us and nor it did spare any part of the world. WHO declared global pandemic on 11th March 2020.

Till $27^{\text {th }}$ July' 2020, the total cases worldwide exceeded 16 million, total deaths more than 650,000 , death rate is much higher in hospital admitted critical patients ${ }^{1}$. The number of affected cases and deaths both have become exponential during this pandemic. In Bangladesh, the total cases till now, more than

1. Professor of Medicine, Popular Medical College

2. Associate Professor of Medicine, Popular Medical College

3. Assistant Professor of Medicine, Dhaka Medical College

4. Consultant of Medicine, Kuwait Bangladesh Moitry Hospital

Address of correspondence: Professor Quazi Tarikul Islam, Professor of Medicine, Popular Medical College Hospital, Dhaka. Email: prof.tarik@gmail.com 
BJM Vol. 31 No. 2 Clinico-demograhic Profile, Treatment Outline and Clinical Outcome of 236 Confirmed Hospitalized

230,000 with death around 3000 (Crude Fatality Rate $1.31 \%)^{2}$. There may be many more undiagnosed suspected cases as we have limited testing facilities. The highest percentage of patients are in Dhaka city $(44 \%)^{2}$. Th physicians death toll is 87 in COVID-19 who works at frontline and serving in other as on 28 July, 2020. More than 500 Health care workers died in each country of USA, Brazil, UK until July 13 according to Amnesty International.

This is a new coronavirus, still evolving, and has put the scientific authority in a great puzzle, we are learning new information every day. Scientific research is going on throughout the world. Severe acute respiratory illness with fever and respiratory symptoms, comprise the main clinical presentations ${ }^{3}$. But unusual manifestations, such as patients without respiratory symptoms, or only very mild symptoms or gastrointestinal symptoms are increasing worldwide ${ }^{4}$. Understanding regional features are always important. A number of studies elaborating local epidemiological and clinical features have been published. ${ }^{5-7} \mathrm{We}$ conducted this multi-centered descriptive study on 236 confirmed COVID-19 cases in 3 different COVID dedicated hospitals (DMCH, KBMH \& $\mathrm{PMCH}$ ) during May to July 2020 period to give a highlight on the epidemiological \& clinical profile along with treatment outcome in our setting in Bangladesh. This could an early documentation for better understanding of our caregiver doctors.

\section{Materials \& Methods:}

a) Study Design:

We conducted a retrospective multicenter descriptive study on epidemiological \& clinical profile along with treatment outcomes of 236 RT-PCR confirmed patients of COVID-19 from COVID dedicated units of 3 hospitals- Dhaka Medical College Hospital (DMCH), Kuwait Bangladesh Moitry Hospital ( KBMH),Popular Medical College Hospital (PMCH) during the period of May to July 2020. The first 2 are Government $\&$ third one is non-government hospital. Our aim was to collect information representing all levels of socio-economic classes of population.

\section{b) Study Population:}

We selected consecutive 236 patients from COVID dedicated isolation wards of the 3 selected hospitals who were confirmed by real-time polymerase chain reaction(RTPCR) and were diagnosed as having COVID19 and who underwent chest X-ray and complete panel of routine laboratory tests. The study was approved by Institutional Ethical review Committee and data were collected retrospectively.
These hospitals follow admission criteria of our national guideline (version 7.0$)^{8}$ : All suspected/ confirmed cases of COVID-19 presenting with Mild case with major risk factor [DM, HTN, IHD, Prior Asthma/COPD/ILD patients, Known CKD, CLD, Known Malignancy, High risk pregnancy, Obesity (BMI>25)] and deteriorating mild cases in home/institutional isolation, Moderate case of clinical or radiological evidence of pneumonia with CRB65 score 1 or more ,Severe Pneumonia and critical illness like ARDS, Sepsis, Septic shock and or Hypoxia ( $\mathrm{SpO} 2<94 \%$ ) in the absence of any clinical signs were included in the enrollment. All cases with respiratory distress admitted for further evaluation and testing.

Around $80 \%$ of COVID-19 infections present as a mild respiratory illness and can generally be managed outside the hospital ${ }^{9}$. So in this analysis, we could not include this mild symptomatic / asymptomatic patients in our study. The remaining $20 \%$ from moderate to critical patients requiring hospitalization were our study population.

\section{c) Data Collection:}

A team of doctors who had been treating these patients extracted the medical records from direct interviewing the patients / attendants after taking the written informed consent $\&$ also from the hospital records. All the data were included in a previously prepared Case Record Form, giving particular ID number to each patient.

The data included contact history, demographic information and clinical presentation including symptoms on admission and co-morbidities, laboratory investigation reports including chest imaging, treatment programs, and clinical outcomes along with duration of hospital stay.

\section{d) Laboratory tests:}

Nasopharyngeal swab specimens from the upper respiratory tract were obtained from all patients at admission were maintained in viral-transport medium. 2019-nCoV was confirmed by real-time RT-PCR. All patients were given chest $\mathrm{x}$-rays on admission. HRCT chest was done in selected patients. On addition, complete panel of routine laboratory tests, including complete blood count, blood biochemistry, CRP, Ddimer, Ferritin and Procalcitonin was also done according to availability $\&$ clinical requirement.

\section{e) Statistical analysis:}

All statistical analysis were carried out using the STATA version 14. Descriptive and inferential statistics were used in this analysis. Frequency and percentages are presented for the categorical variables such as fever, 
cough \& other symptoms and mean \pm standard deviation and median are presented for the continuous variables like age, duration of Hospital stay.

\section{Results:}

236 RT-PCR positive confirmed COVID 19 patients were enrolled in our multi-centered descriptive study over a period of May to July 2020 from COVID dedicated wings of following 3 hospitals of Dhaka city (Table-1).DMCH enrolled 87 paptient, 50 patients were from $\mathrm{KBMH}$ and 99 from the $\mathrm{PMCH}$.

\section{a) Demographic Characteristics:}

Distribution of patients according to age is shown in Figure 1, which revealed the highest percentage of patients belonged to $50-59$ years age range $(26 \%)$. However COVID-19 can infect patient of all ages, no age is immune.

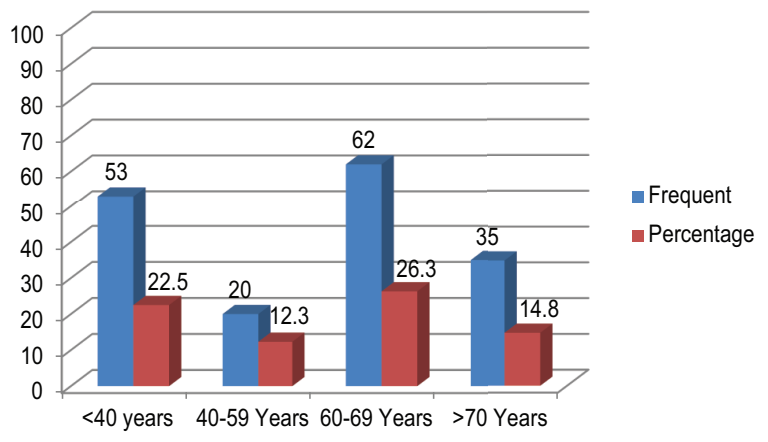

Fig.-1: Distribution of patients according to age

Regarding gender distribution, two-third patients were male $(65 \%) \&$ one-third patients were female $(35 \%)$ (Figure-2)

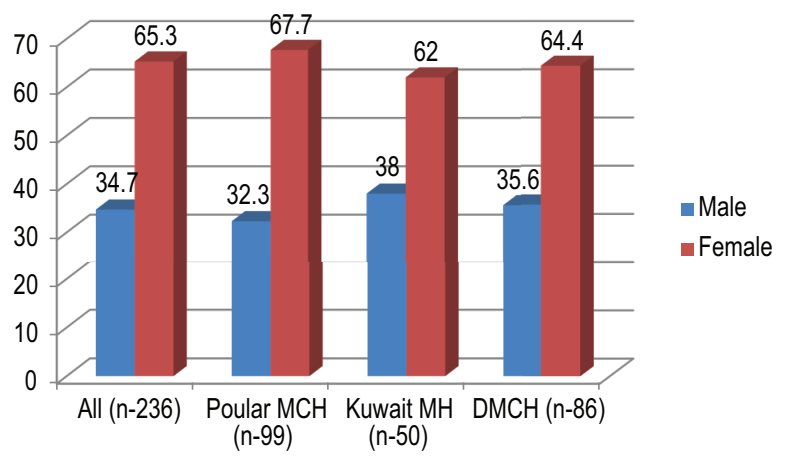

Fig.-2: Distribution of patients according to Gender (N236)

\section{b) Clinical Characteristics \& Co-morbidities:}

The predominant symptoms of our enrolled patients were fever (89\%), cough (85\%) \& dyspnea (76\%) (Figure$3)$. Next common symptoms were fatigue (23\%), chest pain $(23 \%)$, anosmia (19.5\%), anorexia (19\%) \& sore throat $(17 \%)$. Gastro-intestinal symptoms like diarrhea $(13.6 \%)$, altered sense of taste $(12 \%) \&$ vomiting $(11 \%)$ were also presenting complaints.

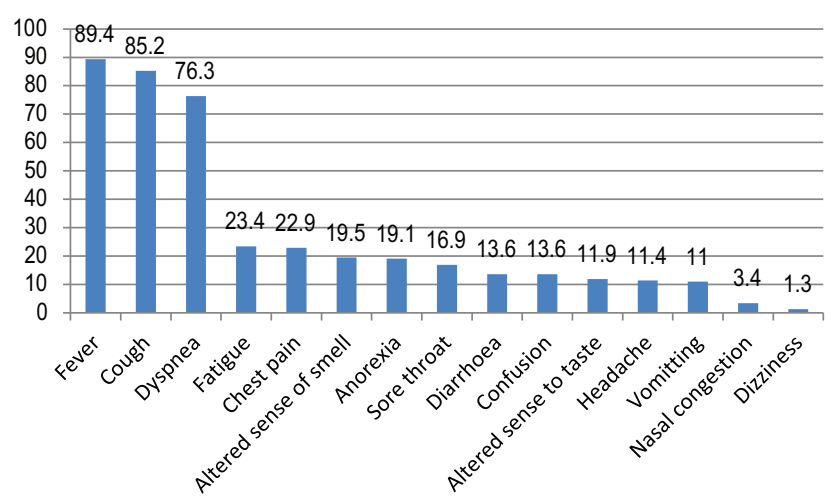

Fig.-3: Clinical Features in enrolled patients (n-236)

Nasal congestion, which is a very common symptom of common cold, was found to be quite uncommon in COVID (3.4\%).Regarding co-morbidities, almost half of the patients had been suffering from Hypertension $(48 \%)$ and Diabetes $(47 \%)$, other less common associated co-morbidities are shown in Figure- 4 .

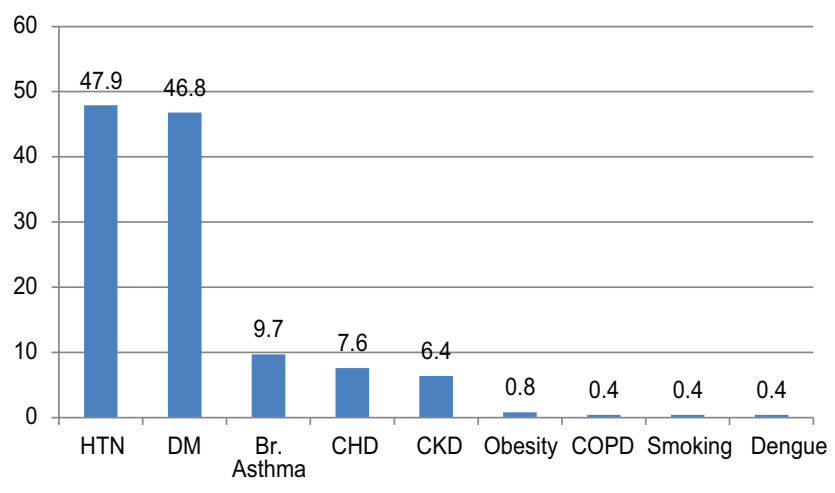

Fig.-4: Co-morbidities in enrolled patients (n-236)

\section{c) Treatment Provided:}

All patients were treated in COVID dedicated isolation units following our National Guideline (version 7.0) \& WHO treatment protocol (Figure-5). 100\% patients received thromboprophylaxis with low molecular weight Heparin (LMWH). Around 2/3 patients received steroid in different forms (Dexamethasone/ Methylprednisolone/ Hydrocortisone) for short duration. Less than half of patients $(47 \%)$ received broad spectrum antibiotics, when there was secondary bacterial infection suspected.

$1 / 3$ of patients received Tocilizumab- monoclonal anti IL-6 antibody, when there was evidence of cytokine 
storm. Other treatment included Remdesevir (24\%), other antiviral drugs (16\%) and Plasma Therapy(06\%), which still have controversial role.

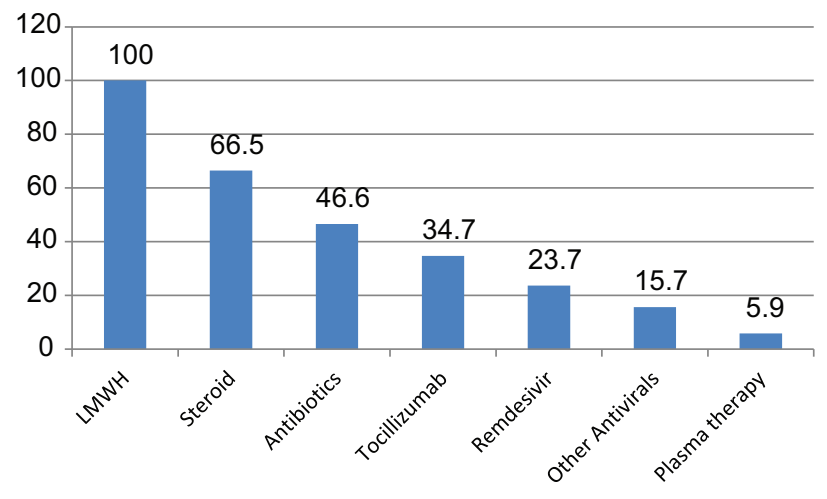

Fig.-5: Treatment provided in enrolled patients (n-236)

\section{d) Treatment Outcome \& Duration of Hospital Stay:}

Among 236 patients, only 20\% patients required ICU management . During our study period, around 64\% was still in hospital, $31 \%$ were discharged, $4.7 \%$ patient died. Total number of death was 11 . Around two-third patients could be discharged in less than 10 days' time, only 3\% patients required longer duration of hospital stay (>30 days).( Figure -06)

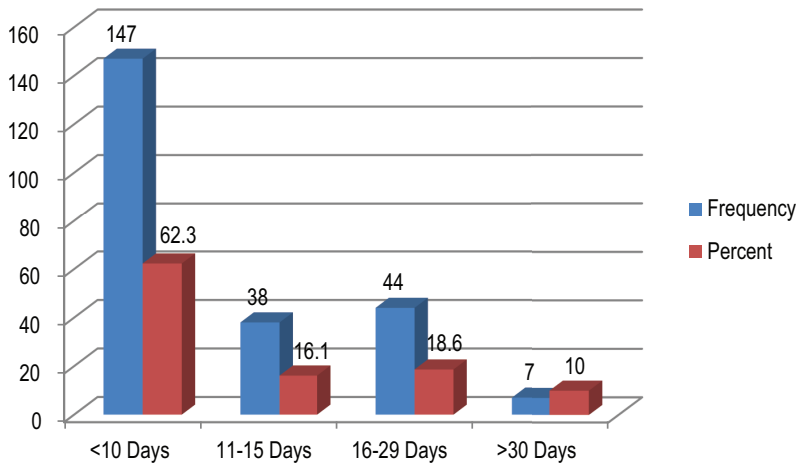

Fig.-6: Duration of Hospital Stay (n-236)

\section{Discussions:}

This report based on multicenter case study of hospitalized COVID-19 patients in Bangladesh, enrolling 236 confirmed cases from 3 different COVID dedicated hospitals. In Bangladesh, highest number of COVID patients are clustered in \& around Dhaka city $(44 \%)^{2}$. Hossain I, et al. have shown that most of the confirmed cases (about 49\%) of Bangladesh reported that they lived in or had come to Dhaka within 14 days before the onset of illness or had been in close contact with any Dhaka resident. ${ }^{10}$ So, this study among the COVID-19 confirmed patients admitted in 3 COVID dedicated hospitals in Dhaka, will give good insight about the epidemiological and clinical characteristics of COVID-19 patients of our country.

Our demographic findings revealed that highest percentage of patients belonging to age range 50-59 years $(26 \%)$, with male predominating( $65 \%$ male, similar with the finding of Asia, e.g. China ${ }^{3}$ (median age: 47 years; $58 \%$ male), India ${ }^{7}$ (mean age 40 years, $67 \%$ male) and other reports from Bangladesh ${ }^{11}$ (Male: female ratio 2.33:1). But studies from America ${ }^{12}$ (median age, 63 years) and Europe ${ }^{7}$ (Median age, 67.5 years) showed higher age of patients, but same male preponderance. Current research suggests that ACE2 is the receptor for COVID-1913, and its expression in men is higher than that in women ${ }^{14}$, which may be the reason for the higher proportion of men with severe illness. The reduced susceptibility of females to viral infections could also be attributed to the protection from X chromosome and sex hormones, which may play an important role in innate and adaptive immunity. ${ }^{15}$

Regarding clinical presentation, the 3 most prevalent symptoms on admission were fever (89\%), cough (85\%) \& dyspnea (76\%), similar to the findings of a systematic review by Rodriguez-Morales et al ${ }^{16}$ of data on 656 cases published in January and February 2020 reported fever(89\%), cough( 58\%)\& dyspnea( 46\%) predominating symptoms. On March 22, 2020, the American Academy of Otolaryngology stated that anosmia and dysgeusia have been reported by patients ultimately testing positive for SARS-CoV-2 and proposed to add these symptoms to the list of screening tools for possible COVID-19 infection. ${ }^{17}$ In April, the U.S. Centers for Disease Control and Prevention updated its list of possible symptoms of COVID-19 to include "new loss of taste or smell". In our study $19.5 \%$ patients presented with altered sense of smell \& $12 \%$ altered sense of taste.

About half of patients infected by COVID 19 had chronic underlying diseases, mainly cardiovascular and cerebrovascular diseases and diabetes ${ }^{18}$; this is similar to our study result. Our results suggest that COVID 19 is more likely to infect older adult males with chronic comorbidities as a result of the weaker immune functions of this patients. ${ }^{19}$

Currently, no anti-viral agents have been proven to be an effective treatment for COVID-19. Remdesavir in hospitalized patients on oxygen was found to have reduced hospital stay but not mortality benefit and hence around $23 \%$ cases in this series received the drug. The study showed treatment of the patients with thromboprophylaxis, oxygen therapy (as needed), judicious use of steroid \& antibiotics along with symptomatic management according to treatment guidelines was suffice. 
The case fatality rate was $4.7 \%$ which seems more than the national data. But these hospitals dealt with the severe and critical illness more than average health care in Bangladesh. The patients in ICU has poor outcome when the patients were ventilated. The hospital stay was less than 10 days in maximum cases indicating good outcome after standard of care provided to patients.

\section{Limitations \& Recommendations:}

Our study has some limitations. Firstly, two-thirds of patients are still hospitalized, so more detailed patient information, particularly regarding clinical outcomes, was unavailable at the time of analysis. Secondly, we could not include mild symptomatic/ asymptomatic patients who were in home isolation \& management. To include their information, we need community level survey.

However, the data in this study permit an early assessment of the epidemiological and clinical characteristics along with current treatment outline of COVID 19 pneumonia in Dhaka, Bangladesh. The outcome of study needs to be further verified by larger sample with multi-centre study with extended followup.

\section{Conclusion:}

Covid-19 in Bangladesh is presented in adult male with fever, cough and dyspnoea predominantly with occasional lack of taste and smell. Hypertension was the common morbidity in majority cases. Supportive care was effective with predominantly good outcome but the mortality was more in ventilated group in ICU.

\section{Acknowledgement:}

I do express my thanks and gratefulness to the team of the following doctors for taking utmost responsibility for data collection of the patients. Dr. Mehedi Hasan, Registrar ICU, PMCH, Dr. Sadia Halima, Asstt. Registrar Medicine, PMCH, Dr. Quazi Audry Rahman, Asstt. Registrar Medicine, PMCH, Dr. Arfa Rahman Ava, Asstt. Registrar Medicine, $\mathrm{PMCH}$.

\section{References:}

1. WHO. Situation report coronavirus (COVID-19)- 134. 10:00 CEST, 28 July 2020. https://www.who.int/ emergencies / diseases / novel-coronavirus-2019/ situation-reports

2. WHO Bangladesh COVID 19 Morbidity and Mortality Weekly Update (MMWU) 27 July 2020 /Vol N022

3. Guan WJ, Ni ZY, Hu Y, Liang WH, Ou CQ, He JX, et al. Clinical Characteristics of Coronavirus Disease 2019 in China. N Engl J Med. 2020;382(18):1708 1720. https://doi.org/10.1056/NEJMoa 2002032 PMid:32109013 PMCid:PMC7092819
4. Pauline V, Diem LV, Arnaud G, Manuel S, Laurent K, Frederique J. Clinical features of covid-19, The wide array of symptoms has implications for the testing strategy. BMJ 2020;369.

5. Huang C, Wang Y, Li X, Ren L, Zhao J, Hu Y, et al. Clinical features of patients infected with 2019 novel coronavirus in Wuhan, China [published correction appears in Lancet. 2020 Jan 30;:]. Lancet. 2020;395 (10223):497506. doi:10.1016/S0140-736(20)30183-5.

5. Gupta N, Agrawal S, Ish P, Mishra S, Gaind R, Usha G, et al. Clinical and epidemiologic profile of the initial COVID-19 patients at a tertiary care centre in India. Monaldi Arch Chest Dis. 2020;90(1):193-6. https:// doi.org/10.4081/monaldi.2020.1294 PMid:32290644

7. Colaneri M, Sacchi P, Zuccaro V, Biscarini S, Sachs M, Roda S, et al. Clinical characteristics of coronavirus disease (COVID-19) early findings from a teaching hospital in Pavia, North Italy, 21 to 28 February 2020. Euro Surveill. 2020;25(16):2000460. 8. National Guidelines on Clinical Management of Coronavirus Disease 2019 (COVID 19) Version 7.0 28 May 2020. https: / / doi.org/ 10.2807/1560-7917.ES.2020. 25.16.2000460. PMid:32347201 PMCid:PMC7189652

9. Wu Z, McGoogan JM. Characteristics of and Important Lessons From the Coronavirus Disease 2019 (COVID19) Outbreak in China. JAMA. 2020. https://doi.org/ 10.1001/jama.2020.2648 PMid:32091533

10. Hossain I, Khan MH, Rahman MS, Mullick AR, Aktaruzzaman MM. The Epidemiological Characteristics of an Outbreak of 2019 Novel Coronavirus Diseases (COVID-19) In Bangladesh: A Descriptive Study. JMSCR. 2020;08(04):544-551. https://doi.org/ $10.18535 / \mathrm{jmscr} / \mathrm{v} 8 \mathrm{i} 4.94$

11. Tian Y, Rong L, Nian W, He Y. Review article: gastrointestinal features in COVID-19 and the possibility of faecal transmission. Aliment PharmacolTher. 2020;51(9):843 851. doi:10.1111/ apt.15731. PMid:32222988 PMCid:PMC7161803

12. Richardson S, Hirsch JS, Narasimhan M, Crawford JM, McGinn T, Davidson KW, and the Northwell COVID-19 Research Consortium. Presenting Characteristics, Comorbidities, and Outcomes Among 5700 Patients Hospitalized With COVID-19 in the New York City Area. JAMA. 2020;323(20):2052-2059. https://doi.org/ 10.1001/jama.2020.6775 PMid:32320003 PMCid:PMC7177629

13. Zhou, P., Yang, X.-L., Wang, X.-G., Hu, B., Zhang, L., Zhang, W., Shi,Z.-L. (2020). Discovery of a novel coronavirus associated with the recent pneumonia outbreak in humans and its potential bat origin. bioRxiv. https://doi.org/10.1101/2020.01.22.914952

14. Zhao, Y., Zhao, Z., Wang, Y., Zhou, Y., Ma, Y., \&Zuo, W. (2020). Single-cell RNA expression profiling of ACE2, the putative receptor of Wuhan 2019-nCov., bioRxiv. https://doi.org/10.1101/2020.01.26.919985 
BJM Vol. 31 No. 2 Clinico-demograhic Profile, Treatment Outline and Clinical Outcome of 236 Confirmed Hospitalized

15. Jaillon S, Berthenet K, Garlanda C Sexual dimorphism in innate immunity Clin Rev Allergy Immunol, 56 (2019), pp. 308-321 Cross Ref View Record in Scopus Google Scholar. https://doi.org/10.1007/s12016-017-8648x PMid:28963611

16. Rodriguez-Morales AJ, Cardona-Ospina JA, GutiérrezOcampo E, et al. Clinical, laboratory and imaging features of COVID-19: a systematic review and metaanalysis. Travel Med Infect Dis 2020:101623. doi: 10.1016/j.tmaid.2020.101623. PMid:32179124 PMCid:PMC7102608

17. https://www.entnet.org/content/aao-hns-anosmiahyposmia-anddysgeusia-symptoms-coronavirusdisease Accessed March 25, 2020.
18. Nanshan C, Min Z, Xuan D et al .Epidemiological and clinical characteristics of 99 cases of 2019 novel coronavirus pneumonia in Wuhan, China: a descriptive study .The Lancet, Volume 395, Issue 10223, 15-21 February 2020, Pages 507-513. https://doi.org/ 10.1016/S0140-6736(20)30211-7

19. M Dryden, M Baguneid, C Eckmann, et al. Pathophysiology and burden of infection in patients with diabetes mellitus and peripheral vascular disease: focus on skin and soft-tissue infections ClinMicrobiol Infect, 21 (suppl 2) (2015), pp. S27-S32 ArticleDownload PDF View Record in Scopus Google Scholar. https:/ /doi.org/ 10.1016/j.cmi.2015.03.024 PMid:26198368. 